\title{
Tratado de Enfermagem em Oncologia
}

https://doi.org/10.32635/2176-9745.RBC.2019v65n1.309

\author{
Oncology Nursing Treaty \\ Tratado de Enfermería Oncológica
}

\author{
Alcântara LL, Cardoso M, Sant'Ana R, Silva R. Lisboa: Chiado Books; 2018. 2 vol. \\ ISBN 978-989-52-2923-9 (versão impressa)
}

Luís Carlos Lopes-Júnior ${ }^{1}$

Em Oncologia, inúmeros e complexos desafios permeiam a prática profissional do cuidado personalizado à pessoa com câncer e à sua família ${ }^{1}$. As descobertas em Oncologia são constantes e requerem a necessidade contínua de se manter atualizado. Por meio das publicaçóes científicas é que surgem as novas ideias, os novos conceitos e todo o progresso nessa área de conhecimento. Ademais, compartilhar experiências é fundamental para a construção de um melhor profissional de saúde que cuida de um paciente com câncer e sua família. De fato, a Oncologia consiste em uma especialização de rápido progresso, sendo um dos grandes objetivos atuais não só alcançar a cura, mas curar com os menores efeitos colaterais e a melhor qualidade de vida possível ${ }^{2}$.

Nesse sentido, a leitura atenta da publicação "Tratado de Enfermagem em Oncologia”, editada por Rita de Cássia Veloso da Silva et al., lançada em agosto de 2018 pela Editora Chiado Books - Lisboa, Portugal, permite reflexôes pertinentes à prática do cuidado em Oncologia.

O Tratado é um compilado de textos de mais de 120 pesquisadores, especialistas em Oncologia, predominantemente do Brasil e de Portugal. Conta ainda com autores da Espanha e do Canadá. Trata-se de autores/pesquisadores respeitados de centros de referência nacionais e internacionais renomados em Oncologia e com larga experiência em pesquisas relacionadas a essa temática. O livro permite ao leitor um conhecimento abrangente sobre um tema complexo e ainda pouco explorado em países em desenvolvimento como o Brasil.

A organização do Tratado está ancorada na tríade: Assistência, Educação/Gestão e Pesquisa em Oncologia. A publicação é dividida em dois volumes que totalizam 40 capítulos. O volume I conta com 25 capítulos, totalizando 698 páginas que abrangem aspectos relacionados à Atenção Integral à Pessoa com Câncer e a seus Cuidadores Formais e Informais. Os capítulos do volume I aprofundam tópicos atinentes da assistência ao paciente oncológico, tais como: 1) A atençâo à família da pessoa com câncer; 2) A importância do cuidar na terminalidade; 3) Problemas éticos vivenciados no cuidado à pessoa com câncer; 4) O impacto do câncer no paciente, na família e na equipe, sob a perspectiva da psico-oncologia; 5) O papel da equipe de saúde na comunicação com o paciente oncológico; 6) Burnout em profissionais de saúde em Oncologia; 7) Sexualidade e câncer; 8) Espiritualidade no cuidado em Oncologia; 9) A musicoterapia como intervenção no cuidado em Oncologia; 10) A experiência da sobrevivência ao câncer; 11) Luto antecipatório e final; 12) A Enfermagem em Quimioterapia; 13) Biossegurança na manipulação de quimioterápicos; 14) Radioterapia; 15) Enfermagem em transplante de células-tronco hematopoiéticas; 16) Manejo seguro de acessos vasculares periféricos; 17) Manejo seguro de acessos vasculares centrais; 18) Cuidados de Enfermagem às pessoas com feridas neoplásicas malignas; 19) A interdisciplinaridade no manejo da dor em Oncologia; 20) O câncer no homem; 21) As diferentes dimensôes do cuidado com a pessoa doente e sua família na Unidade de Terapia Intensiva; 22) Suporte terapêutico complementar em Oncologia; 23) Delirium no contexto dos Cuidados Paliativos; 24) Desidratação no doente sob Cuidados Paliativos; 25) Atenção à fadiga no contexto de Cuidados Paliativos.

${ }^{1}$ Centro de Ciências Biológicas e da Saúde da Universidade Federal de São Carlos (UFSCar). São Carlos (SP), Brasil. Orcid iD: https://orcid.org/0000-0002-2424-6510 Endereço para correspondência: Luís Carlos Lopes-Júnior. Via Washington Luís, Km 235 - Caixa Postal 676. São Carlos (SP), Brasil. CEP 13565-905. E-mail: luisgen@usp.br 
O volume II do Tratado é constituído por 444 páginas e apresenta outros 15 capítulos distribuídos em dois grandes eixos: Educação e Gestão em Oncologia (composto por nove capítulos) e Pesquisa em Oncologia (seis capítulos). No eixo Educação e Gestão em Oncologia, são englobados os seguintes temas: 26) O enfermeiro educador extramuros; 27) Açôes da Enfermagem na prevenção e no controle do câncer; 28) Atuação da Enfermagem no setor de diagnóstico por imagem; 29) Competências do enfermeiro em onco-hematologia; 30) Açóes da Enfermagem na radioiodoterapia; 31) Segurança do paciente na terapêutica oncológica; 32) Indicadores de qualidade na Enfermagem Oncológica; 33) Dimensionamento do quadro de profissionais de Enfermagem em Oncologia; 34) Acreditação em Oncologia.

Já no eixo Pesquisa em Oncologia, temas relevantes e inovadores são abordados: 35) Pesquisa de Enfermagem em Oncologia; 36) Oncologia integrativa; 37) Práticas integrativas e complementares em Oncologia; 38) Aconselhamento genético em câncer; 39) Pesquisa translacional em Oncologia; e 40) Psiconeuroimunologia e câncer.

Pelo exposto, percebe-se o quâo abrangente é o presente Tratado. Isso se traduz pelas mais de 1.100 páginas. Embora longo, a leitura dos capítulos é prazerosa para aqueles que se interessam pelo assunto. Os autores dos capítulos utilizam os recursos de tabelas e figuras para destacar ou resumir alguma informação importante. Também oferecem uma atualizada lista de referências para que o leitor possa consultar. Todos os capítulos começam elencando os objetivos, seguidos por um sumário, resumo e consideraçôes iniciais. Tal estrutura permite ao leitor apreender os principais pontos a serem desenvolvidos no corpo de cada capítulo. Grande parte dos capítulos também apresenta uma seçâo de implicaçóes para prática em Oncologia e conclusão, o que permite ao leitor registrar a informaçáo essencial ou a mais relevante.

De fato, em todos os capítulos, existem passagens relevantes para serem destacadas. Ressalto uma passagem que se encontra no prefácio da publicaçáo permeada de reflexão. Os editores escrevem: "[...] escrito a muitas mãos, assim como deve ser o cuidado qualificado e sensivel em Oncologia".

Embora a clínica, a arte de diagnosticar e tratar seus doentes, não possa se desvincular completamente da especulação experimental, da investigação, que lhe fornece as evidências científicas para a prática clínica, de outro lado, e tão importante quanto, está o cuidado ao paciente com câncer que se beneficiará das descobertas dessas investigaçôes ${ }^{1}$. $\mathrm{O}$ cuidar é muito mais abrangente do que o curar, e mesmo, por vezes, não necessitando de sofisticaçóes tecnológicas, precisa de uma equipe interdisciplinar complexa, bem treinada e, sobretudo, humanizada ${ }^{2,3}$. Nesse sentido, a abordagem multidisciplinar é essencial para o progresso da especialidade Oncologia. Ademais, o sucesso dessa abordagem pode ser visto pela melhoria das curvas de sobrevida em todo o mundo, inclusive em diversos centros brasileiros.

Agradecemos à Rita de Cássia Veloso da Silva e colaboradores pela dedicação e excelente contribuição dada a Oncologia com o presente Tratado.

\section{REFERÊNCIAS}

1. Lopes-Júnior LC, Olson K, de Omena Bomfim E, et al. Translational research and symptom management in oncology nursing. Br J Nurs. 2016;25(10):S12-S21. doi: https://doi.org/10.12968/bjon.2016.25.10.S12.

2. Lopes-Júnior LC, Bomfim EO, Nascimento LC, et al. Non-pharmacological interventions to manage fatigue and psychological stress in children and adolescents with cancer: an integrative review. Eur J Cancer Care (Engl). 2016;25(6):921-935. doi: https://doi.org/10.1111/ecc.12381.

3. Lopes Júnior LC, Silva GP, Nascimento LC, Lima RAG. Cuidados de enfermagem à criança e ao adolescente com câncer e à sua família. In: Associação Brasileira de Enfermagem; Gaíva MAM, Ribeiro CA, Rodrigues EC, organizadores. PROENF Programa de Atualização em Enfermagem: Saúde da Criança e do Adolescente: Ciclo 9. Porto Alegre: Artmed Panamericana; 2015. p. 87-154. (Sistema de Educação Continuada a Distância, v. 4). 